Article

\title{
Incineration of Pre-Treated Municipal Solid Waste (MSW) for Energy Co-Generation in a Non-Densely Populated Area
}

\author{
Ettore Trulli $^{1}$, Vincenzo Torretta ${ }^{2, *}$, Massimo Raboni $^{2}$ and Salvatore Masi $^{1}$ \\ 1 School of Engineering, University of Basilicata, Viale dell'Ateneo Lucano 10, \\ Potenza I-85100, Italy; E-Mails: ettore.trulli@unibas.it (E.T.); salvatore.masi@unibas.it (S.M.) \\ 2 Department of Biotechnologies and Life Sciences, Insubria University, Via G.B. Vico 46, \\ Varese I-21100, Italy; E-Mail: massimo.raboni@uninsubria.it
}

* Author to whom correspondence should be addressed; E-Mail: vincenzo.torretta@uninsubria.it; Tel.: +39-0332-218-782; Fax: +39-0332-218-779.

Received: 12 September 2013; in revised form: 3 December 2013 / Accepted: 4 December 2013 / Published: 12 December 2013

\begin{abstract}
The planning actions in municipal solid waste (MSW) management must follow strategies aimed at obtaining economies of scale. At the regional basin, a proper feasibility analysis of treatment and disposal plants should be based on the collection and analysis of data available on production rate and technological characteristics of waste. Considering the regulations constraint, the energy recovery is limited by the creation of small or medium-sized incineration plants, while separated collection strongly influences the heating value of the residual MSW. Moreover, separated collection of organic fraction in non-densely populated area is burdensome and difficult to manage. The paper shows the results of the analysis carried out to evaluate the potential energy recovery using a combined cycle for the incineration of mechanically pre-treated MSW in Basilicata, a non-densely populated region in Southern Italy. In order to focalize the role of sieving as pre-treatment, the evaluation on the MSW sieved fraction heating value was presented. Co-generative (heat and power production) plant was compared to other MSW management solutions (e.g., direct landfilling), also considering the environmental impact in terms of greenhouse gases (GHGs) emissions.
\end{abstract}

Keywords: combined cycle; energy recovery; greenhouse gases emissions; incineration; municipal solid waste management; sieving 


\section{Symbols}

\begin{tabular}{|c|c|c|c|c|c|}
\hline$c$ & constant pressure specific heat & $\beta$ & pressure ratio & $f$ & gases \\
\hline$h$ & Enthalpy & $\varepsilon$ & efficiency & $f a$ & flying ashes \\
\hline$H V$ & heating value & $\eta_{I}$ & first-principle yield & $g$ & gas \\
\hline$k$ & adiabatic law exponent & $\eta_{I I}$ & second-principle yield & $g-g$ & gas-gas heat exchanger \\
\hline$m$ & mass flow & $\eta$ & total efficiency & $G T$ & gas turbine \\
\hline$n$ & air index & $\chi$ & coefficient & $g-w$ & gas-water heat exchanger \\
\hline$P$ & Pressure & $\tau$ & environmental temperature & $s g$ & slag \\
\hline$Q$ & co-generated thermal power & \multicolumn{1}{|c|}{} & finite difference & $s t$ & steam \\
\hline$S$ & Entropy & & & $S T$ & steam turbine \\
\hline$T$ & Temperature & & Subscripts & $s w$ & solid waste \\
\hline$W$ & electrical power & $a e$ & air in excess & $w$ & water \\
\hline$Y$ & Yield & \multirow{2}{*}{$a t$} & theoretical air & \multicolumn{2}{c|}{$\begin{array}{c}0,1,2,3,4,5,6,7,8,9 \\
\text { calculation section }\end{array}$} \\
\hline
\end{tabular}

\section{Introduction}

The main objective in integrated solid waste management (ISWM) [1,2] is to implement technologies that reduce the environmental pressure by recovering both the fractions with a considerable value on the market and the non-traditional ones (e.g., organic [3-8], medical [9-11], automotive shredder residues [12], WEEE [13]). Moreover, any good management system also includes the involvement of the people, who have to be aware of the environmental benefits and of the reduced danger to health that results from a correct behavior [14,15]. Such an objective is highlighted by European Union (EU) legislation, which produced several Directives on waste disposal, treatment and incineration [16-19]. Such Directives: (i) prohibit waste recovery and disposal that have a negative impact on both the human health and the environment; (ii) aim at the reduction of waste production as well as the promotion of the reuse, the recycling and the recovery activities. The Italian Government acknowledged these Directives [20,21], also imposing the energy recovery from waste incineration.

According to the above-mentioned regulations and principles, the ISWM should both reduce landfilling and increase energy and materials recovery in order to lower environmental impact, energy resources consumption and economic costs. For example, landfilling of energy-rich waste should be avoided as far as possible, partly because of the negative environmental impacts of the technique, but mainly because of the low resources recovery [22].

Various types of Life-Cycle-Analysis (LCA) have been proposed for determining the most environmental-sound ISWM procedure [23,24]. Most of them focus on high percentages of separated collection in relatively small and densely populated area: some examples are described in [25-28]. However, in a scarcely-populated area, the environmental (e.g., GHG emissions) and economic impact of MSW collection is high because of fuel consumption [25,29,30]. The ISWM issue in a non-densely populated area concerns developing and developed countries. For example, $60 \%$ of EU surface has a population density of less than 100 inhab $\mathrm{km}^{-2}$ [31].

In order to reduce the landfill volumes as well as to close the MSW cycle, a solution can be the waste incineration with energy recovery [32]. Therefore, excluding direct landfilling of MSW, the solutions for ISWM are essentially three (Figure 1): direct burning of the raw MSW; accelerated 
stabilization of the whole MSW prior to incineration; MSW mechanical pre-treatment with secondary fuel (or RDF) production prior to incineration and organic matter aerobic stabilization (the so-called biostabilization) before landfilling.

Figure 1. Typical municipal solid waste (MSW) treatment options.

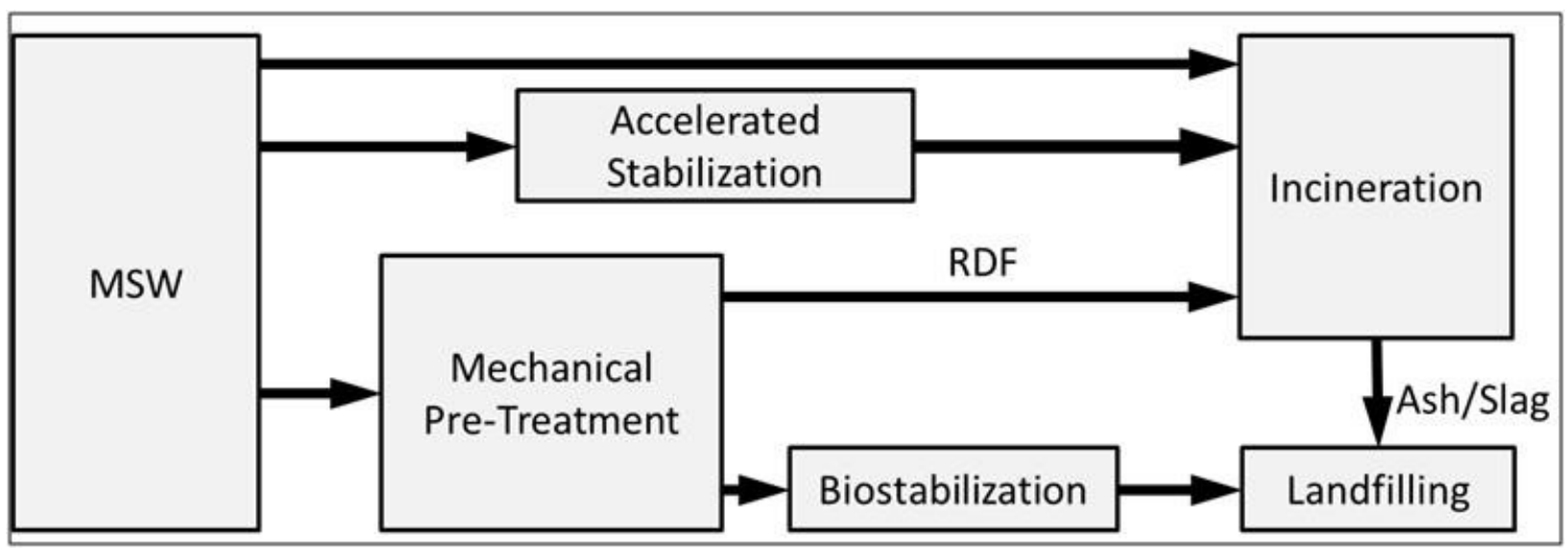

Regarding the last solution, the mechanical pre-treatment of waste by sieving has aroused great interest, because it influences the MSW volumes addressed for both incineration and landfilling [33]; as consequence, the process reduces the environmental impact of the whole ISWM system. Sieving is carried out on raw waste and it allows separating out a flow of material that is characterized by a higher energy content (heating value, $H V$, and net calorific value, NCV) [34]. The separation leads to a reduction in the combustion section, even if it partly penalizes the energy recovery. Moreover, in plants which treat waste coming from basins with different waste management policies, the pre-treatment process allows to guarantee a better quality of secondary fuel.

The case study presented in this paper regards the methodological approach applied to determine which technical solution may be proposed for solving some ISWM issues in a non-densely populated area, with specific reference to Basilicata, an Italian region. The analysis of the MSW composition and quantity (current situation and future trend) has been carried out. The results, combined with the waste size characterization, allowed to define the optimal mechanical pre-treatment in order to achieve an optimal balance between GHGs emissions and heat-and-power production.

\section{Materials and Methods}

\subsection{Investigated Area}

Basilicata is a predominantly mountainous region (Figure $2 \mathrm{a}$ ) that covers about $10,000 \mathrm{~km}^{2}$ in the center of Southern Italy. The population is less than 580,000 inhabitants [35]. Most of the 131 districts have a population below 3000 inhab with an average population density varying between 31 and 380 inhab km ${ }^{-2}$ (average: 57 inhab km ${ }^{-2}$; Figure $2 b$ ). 
Figure 2. Average altitude (a) and population density (b) in Basilicata region.

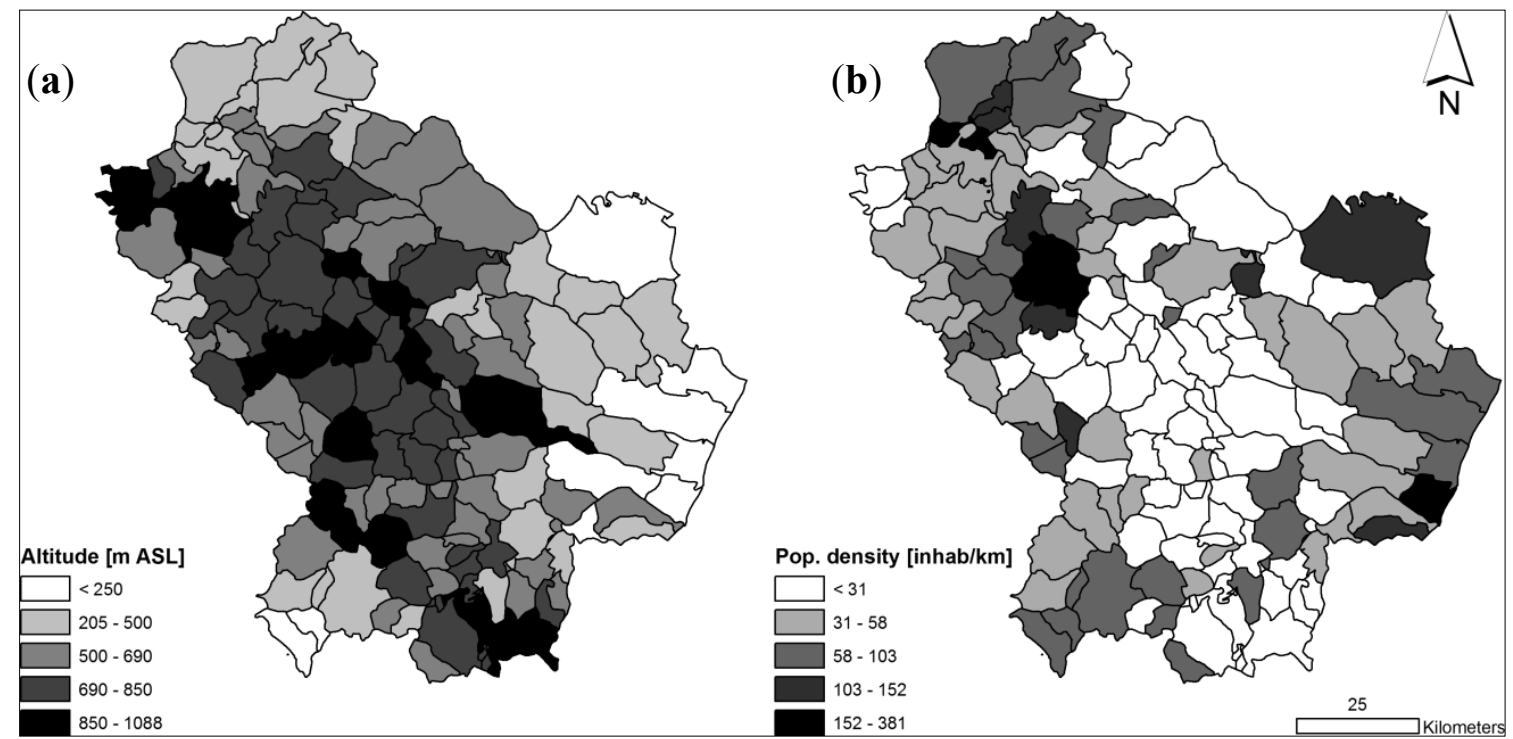

The average MSW production (1.08 $\mathrm{kg}$ inhab $\left.^{-1} \mathrm{~d}^{-1}\right)$ is less than the national average [36,37]. During the last few years, a $2 \% \mathrm{y}^{-1}$ increase in the MSW average production occurred, with peaks of $5 \% \mathrm{y}^{-1}$ in the largest towns.

\subsection{Characteristics of Waste Production}

A survey was carried out with the aim of determining both the sieved waste composition and the influence on the combustible waste characteristics [37]. The mesh size was determined by considering that it has a considerable effect on the quantity of the obtainable energy [38].

Experimental tests were carried out on the waste collected in urban centers, with a production rate that fell in the range $0.8-1.2 \mathrm{~kg}$ inhab ${ }^{-1} \mathrm{~d}^{-1}$. The percentages of separation by sieving were determined experimentally and the different product fraction percentages were deduced on the basis of the average composition of the waste. The data was determined as a function of the amount, in terms of weight, of the individual fractions of over-sieved (OS) and under-sieved (US) waste. This data can be extended to all compositions, on the assumption that if the amount, in terms of weight, of the single fraction is varied, the size does not change. Predictions in MSW evolution concerning quantity and composition were carried out considering: (i) past data; (ii) population growth; (iii) evolution of policies regarding separated collection [36].

The $H V$ of each fraction was estimated using data found in scientific literature [32,39] (organic: 2,930.2 $\mathrm{kJ} \mathrm{kg}^{-1}$; paper: 12,558.0 kJ kg-1; plastic and rubber: $20,930.0 \mathrm{~kJ} \mathrm{~kg}^{-1}$; wood, textile and leather: 15,488.2 $\mathrm{kJ} \mathrm{kg}^{-1}$; under-sieved waste below $20 \mathrm{~mm}: 5,651.1 \mathrm{~kJ} \mathrm{~kg}^{-1}$ ) and was applied to each OS fraction in order to obtain the respective energy content.

\subsection{Environmental Effects Assessment}

The GHGs emission assessment of three ISWM possible solution was carried out considering the influence of the sieve cut-off [40]. Such solutions are: (a) the direct MSW landfilling; (b) US landfilling and OS incineration; (c) US biostabilization and OS incineration. Table 1 reports the emission factors assumed for the environmental assessment [40,41]. 
Table 1. Emission factors adopted for the environmental effects assessment.

\begin{tabular}{|c|c|c|c|}
\hline \multirow{2}{*}{\multicolumn{2}{|c|}{ Treatment }} & \multicolumn{2}{|l|}{ GHGs emissions } \\
\hline & & Unit & Value \\
\hline \multirow{2}{*}{ Biostabilization } & without energy recovery & \multirow{2}{*}{$\mathrm{kg} \mathrm{CH}_{4} \mathrm{eq} \mathrm{kg}^{-1}$ biodegradable VSS } & 2.5 \\
\hline & with energy recovery & & 1.5 \\
\hline Incineration plant & $50 \%$ of biodegradable fraction removal & $\mathrm{kg} \mathrm{CH}_{4} \mathrm{eq} \mathrm{kg}^{-1} \mathrm{VSS}$ & 1.5 \\
\hline \multirow{2}{*}{$\begin{array}{l}\text { Landfilling ( } 50 \% \\
\text { of biogas capture) }\end{array}$} & without energy recovery & \multirow{2}{*}{$\mathrm{kg} \mathrm{CH}_{4} \mathrm{eq} \mathrm{kg}^{-1}$ biodegradable VSS } & 10.5 \\
\hline & with energy recovery & & 9.5 \\
\hline
\end{tabular}

\subsection{Modeling}

\subsubsection{Process and Model Description}

The combined gas-steam power cycle plant (Rankine-Brayton cycle [42]) for power and heat production may be regarded as one of the best strategies for MSW management, in terms of efficiency, pollution and management costs [43-45]. The layout of the examined plant is shown in Figure 3.

Figure 3. The examined combined cycle plant layout. Numbers indicates the calculation sections.

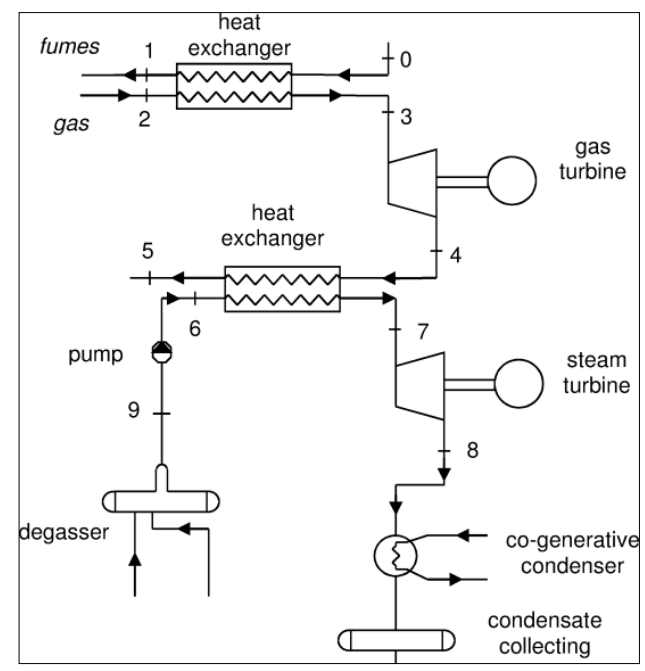

The thermal cycle used for power recovery is composed of a gas turbine coupled with a water steam cycle, where the heat entering the steam cycle is obtained from the thermal recovery carried out on the gas turbine exhaust. Before being sent for treatment, the high-temperature combustion gases go through a heat exchanger, where heat is transferred, and what comes out is a liquid at a lower temperature. Then the heated and compressed air is sent to the gas turbine. The emitted gases are introduced into a steam generator. A mono-phase counter-pressure steam turbine was considered. The plant is completed by an electrical power generator and by the heat exchangers for producing hot water. Moreover, the plant includes a condensate collector, centrifuge pumps and a degasser for treating the condensate water and the steam. For the gas-gas heat exchanger a Ljungström-type rotating system [46] was used.

In the case of combustion under practical conditions $(n>1)$, the exhaust gas discharge is equal to:

$$
m_{f}=m_{s w}-\left(m_{s g}+m_{f a}\right)+m_{a e}
$$


In order to calculate the above terms, we used the following equations:

$$
\begin{gathered}
m_{s g}=\chi_{s g} \cdot m_{s w} \\
m_{f a}=\chi_{f a} \cdot m_{s w} \\
m_{a t}=\chi_{a t} \cdot m_{s w} \\
m_{a e}=n \cdot m_{a t}
\end{gathered}
$$

If there are no unburned substances, and no heat exchange between the gases and the combustion chamber, the gas temperature only depends on the fuel characteristics, the air index $n$ as well as the initial air and fuel temperatures. In practice, a temperature $T_{f}$ equal to the theoretical combustion temperature, $T_{a d}$, is considered:

$$
T_{a d}=\tau+\frac{H V}{c_{f} \cdot\left(n \cdot m_{a t}\right)}
$$

The temperature of the gas entering the turbine is given by the equation below, by accepting for the gas-gas exchanger an efficiency of $\varepsilon_{g-g}$ :

$$
T_{3}=T_{2}+\frac{\varepsilon_{g-g}\left(m_{f} \cdot c_{f}\right) \Delta T_{0-2}}{m_{g} \cdot c_{g}}
$$

The temperature of the gas leaving the turbine, considering the 3-4 adiabatic transformation (Figure 3) as reversible, is given by the following equation:

$$
T_{4}=T_{3} \cdot \beta^{(1-k) / k}
$$

The electrical power, produced by the alternator coupled to the gas turbine, is given by the equation:

$$
W_{G T}=\eta_{G T} \cdot\left(m_{g} \cdot c_{G T}\right) \cdot \Delta T_{3-4}
$$

With an efficiency of the air-water heat exchanger of $\varepsilon_{g-w}$, the steam discharge in the turbine is:

$$
m_{S T}=\frac{\left(m_{g} c_{G T}\right) \cdot \varepsilon_{g-w} \cdot \Delta T_{4-6}}{\Delta h_{7-6}}
$$

Considering a total efficiency $\eta_{S T}$ for the steam turbine section, the electrical power developed is:

$$
W_{S T}=\eta_{S T} \cdot m_{S T} \cdot \Delta h_{7-8}
$$

The steam/water heat exchanger operates with a gradient of $\boldsymbol{\Delta} T_{7-6}$.

The co-generated thermal energy is equal to:

$$
Q=m_{s} \cdot \Delta h_{8-9}
$$

A water discharge is transferred, and is equal to:

$$
m_{W}=\frac{Q}{c_{W} \cdot \Delta T_{7-6}}
$$

The first-principle yield of the co-generative combined cycle plant $\left(\eta_{I}\right)$ is:

$$
\eta_{I}=\frac{W_{S T}+W_{G T}+Q}{m_{s w} \cdot H V}
$$


The yield is lower because a part of $Q$ is wasted while it is transported to the heating.

In co-generative plants, we also consider a second-principle yield $\left(\eta_{I I}\right)$ which takes into account that the quantity of electrical power is much greater than the thermal power.

The analyzed energy is intended as the work, which can be obtained as a system returns to steady conditions. In the components of work production, the energy flow coincides with the electrical power; in the condenser, the energy flow is lower than the thermal flow because of the increase in the exchange fluid entropy. The available energy entering the plant coincides with the thermal power produced by the waste combustion. In the case of electricity generation only, $\eta_{I I}$ is equivalent to $\eta_{I}$. In the case of co-generation we have:

$$
\eta_{I I}=\frac{W_{S T}+W_{G T}+Q-\left(m_{W} \cdot T_{W} \cdot \Delta s\right)}{m_{s w} \cdot H V}
$$

In order to use the waste heating value as a heating source for summer air-conditioning, we consider a value $Y$ for the refrigeration yield; therefore we have:

$$
\eta_{\text {I summer }}=\frac{W_{S T}+W_{G T}+Y \cdot Q_{s w}}{m_{s w} \cdot H V}
$$

\subsubsection{Data and Assumptions}

The waste-to-energy plant is:

- intended to produce power and low temperature heat for feeding a heating network;

- situated in a strategic area that can be reached from every town through the ordinary communication routes;

- provided with a landfill in order to reduce the transportation of residual waste (e.g., ash, slag).

The $H V$ of the secondary fuel used in the incineration plant results from the MSW analysis.

Table 2 shows the values of the parameters used in the calculation.

\begin{tabular}{|c|c|c|c|c|}
\hline \multicolumn{3}{|c|}{ Parameter } & Unit & Value \\
\hline \multirow{2}{*}{ Coefficients } & \multirow{2}{*}{\multicolumn{2}{|c|}{$\begin{array}{l}\text { theoretical combustion air }\left(m_{a t} / m_{s w}\right) \\
\text { air index }(n)\end{array}$}} & - & 4.300 \\
\hline & & & - & 2.300 \\
\hline \multirow{2}{*}{ Production rates } & \multirow{2}{*}{\multicolumn{2}{|c|}{$\begin{array}{c}\text { slag }\left(\chi_{s g}\right) \\
\text { flying ash }\left(\chi_{f a}\right)\end{array}$}} & $\mathrm{kg} \mathrm{kg}^{-1}$ & 0.055 \\
\hline & & & $\mathrm{kg} \mathrm{kg}^{-1}$ & 0.188 \\
\hline \multirow{4}{*}{ Specific heats } & \multirow{4}{*}{\multicolumn{2}{|c|}{$\begin{array}{l}\text { gases } \\
\text { gas entering the turbine } \\
\text { gas leaving the turbine } \\
\text { steam entering the turbine }\end{array}$}} & $\mathrm{kJ} \mathrm{kg}^{-1} \mathrm{~K}^{-1}$ & 1.260 \\
\hline & & & $\mathrm{kJ} \mathrm{kg}^{-1} \mathrm{~K}^{-1}$ & 1.009 \\
\hline & & & $\mathrm{kJ} \mathrm{kg}^{-1} \mathrm{~K}^{-1}$ & 1.165 \\
\hline & & & $\mathrm{kJ} \mathrm{kg}^{-1} \mathrm{~K}^{-1}$ & 1.091 \\
\hline \multirow{5}{*}{ Yield } & \multirow{2}{*}{ heat exchanger } & gas-gas $\left(\varepsilon_{g-g}\right)$ & - & 0.950 \\
\hline & & gas-water $\left(\varepsilon_{g_{-w}}\right)$ & - & 0.700 \\
\hline & \multirow{2}{*}{ Turbine } & gas-fed & - & 0.730 \\
\hline & & steam-fed & - & 0.730 \\
\hline & \multicolumn{2}{|c|}{ refrigerating machine $(Y)$} & - & 0.800 \\
\hline
\end{tabular}

Table 2. Parameters for combustion calculations.

The combustion gas temperature, $T_{f}$, is $95^{\circ} \mathrm{C}$. 


\section{Results and Discussion}

\subsection{Waste Production and Energy Potential Evolution}

Figure 4 shows the estimation of waste production as a function of different percentages of separated waste collection.

Figure 4. Waste production trend as a function of separated waste collection.

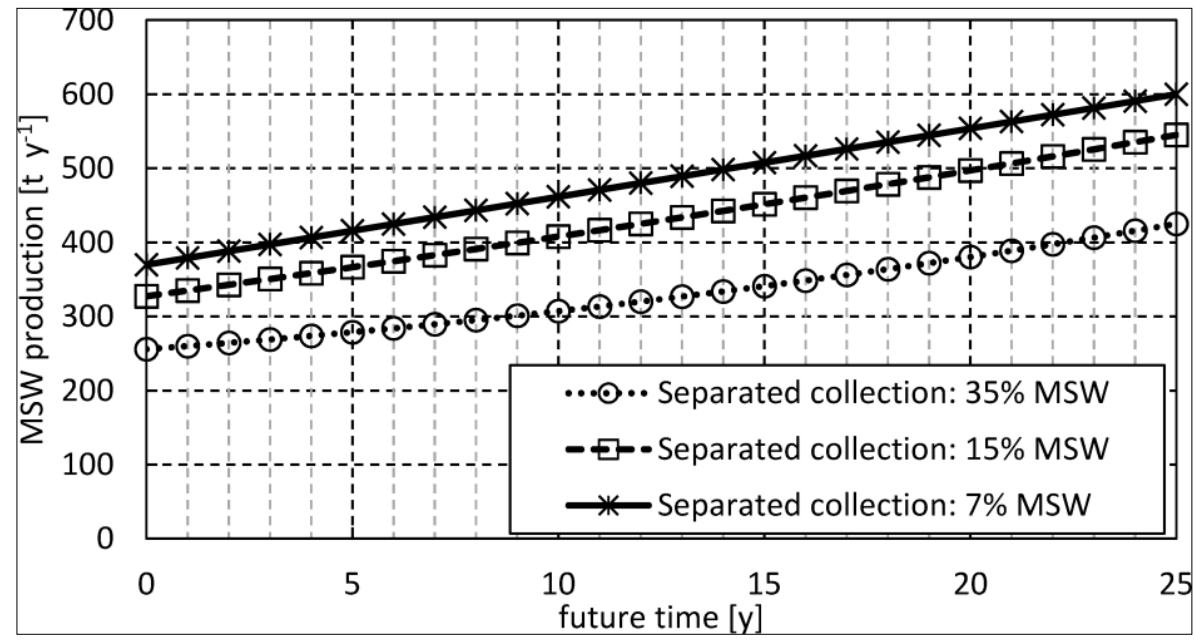

In the next 25 years the MSW production will increase almost linearly, reaching values of 420 and $600 \mathrm{t} \mathrm{y}^{-1}$ considering, respectively, the optimistic (35\%) and the pessimistic (7\%) percentages of separated collection.

Concerning the current composition (Table 3, second column), the MSW production varies greatly. The amount of biodegradable organic waste is equal to about $0.350 \mathrm{~kg}^{\text {inhab }} \mathrm{d}^{-1}$, while the maximum level of paper and plastic collection is $50 \%$ of the national average. In the next decade, Basilicata MSW production will be involved in quality variations which will be more remarkable than the quantity ones. Figure 5 shows the results of an estimation of the waste composition in the next $12 \mathrm{y}$.

Figure 5. Estimation of the MSW composition in Basilicata.

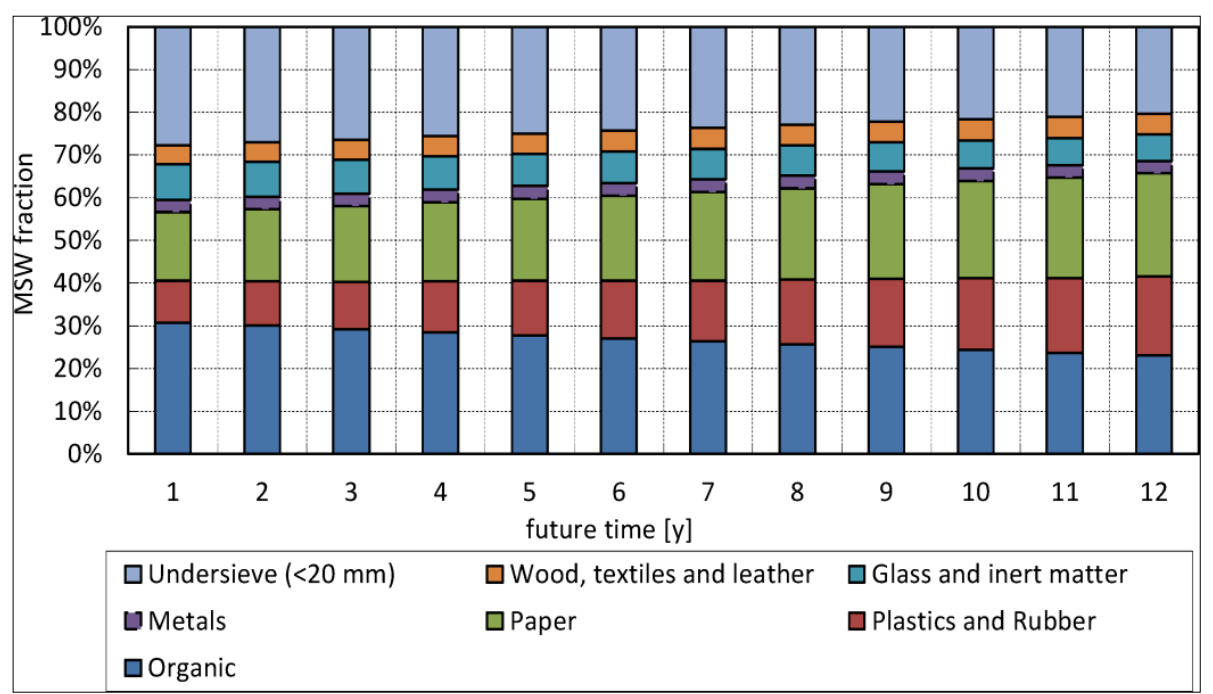


A strong reduction of organic fraction $(-7.6 \%)$, a light reduction of glass $(-2.2 \%)$, a negligible variation of metals, a sensitive increase of papers and plastics $(+8.8 \%$ and $+8.6 \%$, respectively) and a light increase of wood and textiles $(+0.5 \%)$ will occur.

Table 3 reports the data relative to the percentage composition of the OS MSW. About half of the waste is smaller than $60 \mathrm{~mm}$ and less than $20 \%$ is composed by the fine fraction $(<20 \mathrm{~mm})$. The composition of the oversized fraction $(>120 \mathrm{~mm}$ ) largely depends on the high HV materials (plastic, paper and textiles), while the major part of the organic fraction is below $60 \mathrm{~mm}$. Glass and inert matter have a homogeneous distribution.

Table 3. Percentage composition of both raw and over-sieved (OS) MSW.

\begin{tabular}{ccccccc}
\hline \multirow{2}{*}{ MSW fraction } & Raw & \multicolumn{5}{c}{ Sieve cut-off [mm] } \\
\cline { 3 - 7 } & MSW & $\mathbf{4 0}$ & $\mathbf{6 0}$ & $\mathbf{8 0}$ & $\mathbf{1 0 0}$ & $\mathbf{1 2 0}$ \\
\hline Organic & $\mathbf{3 4 . 3}$ & 70.3 & 39.6 & 24.3 & 13.3 & 6.4 \\
Paper & $\mathbf{2 0 . 5}$ & 96.1 & 83.5 & 77.7 & 69.1 & 59.4 \\
Plastic and rubber & $\mathbf{1 1 . 4}$ & 93.5 & 83.2 & 81.3 & 73.9 & 63.4 \\
Wood, textile and leather & $\mathbf{5 . 4}$ & 85.3 & 70.3 & 63.7 & 61.9 & 59.8 \\
Glass and inert matter & $\mathbf{6 . 6}$ & 89.7 & 67.1 & 50.3 & 32.4 & 15.8 \\
Metals & $\mathbf{3 . 0}$ & 88.3 & 82.9 & 73.3 & 57.9 & 49.3 \\
Under-sieved (20 mm) & $\mathbf{1 8 . 8}$ & - & - & - & - & - \\
\hline Total & $\mathbf{1 0 0 . 0}$ & $\mathbf{6 7 . 6}$ & $\mathbf{5 0 . 9}$ & $\mathbf{4 2 . 5}$ & $\mathbf{3 4 . 4}$ & $\mathbf{2 7 . 4}$ \\
\hline
\end{tabular}

Table 4 shows the HV of separated waste as a function of the sieve size.

Table 4. Heating value (in $\mathrm{kJ} \mathrm{kg}^{-1}$ ) of the over-sieved MSW fraction.

\begin{tabular}{cccccccc}
\hline \multirow{2}{*}{ MSW fraction } & \multirow{2}{*}{ Raw MSW } & \multicolumn{7}{c}{ Sieve cut-off [mm] } \\
\cline { 3 - 8 } & & $\mathbf{2 0}$ & $\mathbf{4 0}$ & $\mathbf{6 0}$ & $\mathbf{8 0}$ & $\mathbf{1 0 0}$ & $\mathbf{1 2 0}$ \\
\hline Organic & $1,004.0$ & $1,236.6$ & $1,043.4$ & 781.1 & 574.1 & 388.4 & 234.8 \\
Paper & $2,576.0$ & $3,172.9$ & $3,659.7$ & $4,225.7$ & $4,709.7$ & $5,177.5$ & $5,591.8$ \\
Plastic and rubber & $2,378.2$ & $2,929.2$ & $3,287.3$ & $3,887.2$ & $4,549.6$ & $5,112.0$ & $5,510.1$ \\
Wood, textile and leather & 840.2 & $1,034.9$ & $1,059.6$ & $1,160.4$ & $1,259.4$ & $1,512.9$ & $1,836.2$ \\
Glass and inert matter & - & - & - & - & - & - & - \\
Metals & - & - & - & - & - & - & - \\
Under-sieved & $5,651.1$ & $1,063.1$ & - & - & - & - & - \\
\hline Total & $\mathbf{6 , 8 6 1 . 4}$ & $\mathbf{8 , 3 7 3 . 6}$ & $\mathbf{9 , 0 5 0 . 0}$ & $\mathbf{1 0 , 0 5 4 . 4}$ & $\mathbf{1 1 , 0 9 2 . 8}$ & $\mathbf{1 2 , 1 9 0 . 8}$ & $\mathbf{1 3 , 1 7 2 . 9}$ \\
\hline
\end{tabular}

Considering the HV as a function of the MSW sieve cut-off, the trend is almost linear: the energy content of the fine fraction is about $64 \%$ of the oversized fraction $(>120 \mathrm{~mm})$.

\subsection{Modeling}

\subsubsection{Environmental Effects}

Figure 6 shows the GHGs emissions for three proposed ISWM solutions.

As expected, the solution with direct landfilling (solution a) generates the highest emissions (e.g., biomethane). In areas where a low waste production occurs (such as Basilicata), the effect is more 
evident because of the long residence times of waste before the landfill closure and the biogas extraction network completion. The direct US landfilling coupled with OS incineration (solution b) generates more GHGs when the amount of burned MSW diminishes. The sieve cut-off influences also landfill volumes uses and energy recovery. In fact, smaller is the sieve cut-off $(20-40 \mathrm{~mm})$, the higher is the waste volume reduction; conversely, higher is the sieve cut-off $(60-80 \mathrm{~mm})$, the lower is the waste volume reduction and the higher is the energy recovery. The separation of the wet fraction, which is first aerobically stabilized in reactors and later disposed of in landfills (solution c) is the best solution, independently from the sieve cut-off; moreover, it allows to decrease the incineration unit size (theoretically, partly penalizing the potential energy recovery). We must also take into account that this phase will be gradually reduced by successively boosting of home composting.

Figure 6. Greenhouse gases (GHGs) emissions for different integrated solid waste management (ISWM) solutions.

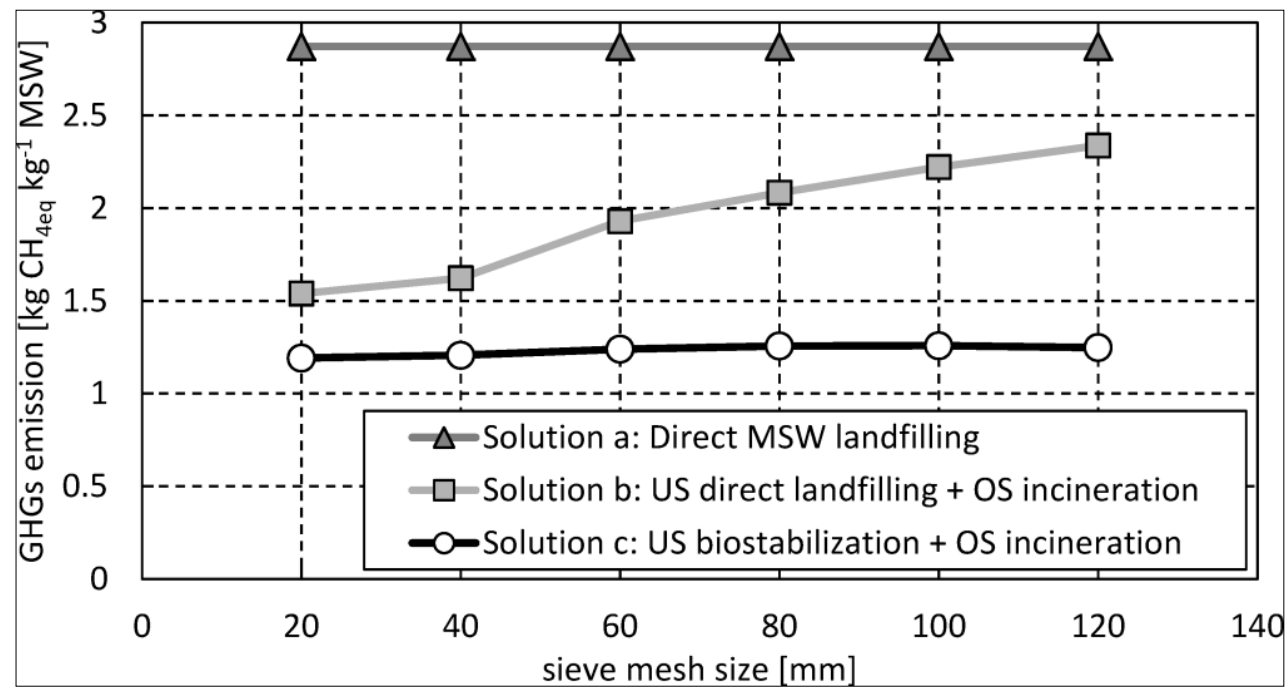

\subsubsection{Waste Incineration and Energy Recovery}

According to an optimization procedure which considers a compromise between the environmental impact (GHG emissions) and the energy recovery, the sieve cut-off was set equal to $60 \mathrm{~mm}$, corresponding to an $H V$ equal to about $10.1 \mathrm{MJ} \mathrm{kg}^{-1}$ (Table 4).

For the gas-gas heat exchanger, the discharge is $m_{G T}=1.3 m_{f}\left(m_{f}=60 \mathrm{~kg} \mathrm{~s}^{-1}\right)$ using a gas temperature in the turbine, $T_{3}$ equal to $884{ }^{\circ} \mathrm{C}$. The operating conditions of the gas turbine are: entry pressure of $9.1 \mathrm{kPa}$; pressure ratio $(\beta)$ equal to 7.1 . The entry temperature and pressure into the turbine are 60 bar and $440{ }^{\circ} \mathrm{C}$, respectively. At the output, there is an optimum level for operation of the turbine, which is no lower than 0.9 , and a temperature of approximately $100{ }^{\circ} \mathrm{C}$. With a steam discharge equal to $8.4 \mathrm{~kg} \mathrm{~s}^{-1}$, the power produced by the alternator coupled with the gas turbine is 25.1 MW. The power developed by the steam turbine is $5.4 \mathrm{MW}$ with a gradient that can be used to produce $30{ }^{\circ} \mathrm{C}$ hot water. The co-generated thermal power, $Q$, is $16.8 \mathrm{MW}$, which is transferred to a water flow, $m_{w}$, of $200 \mathrm{~kg} \mathrm{~s}^{-1}$.

The second-principle yield $\left(\eta_{I I}\right)$, in the case of power generation only, is 0.47 , while the first- and second-principle yields related to co-generation are 0.74 and 0.54 , respectively. In the case of a demand for cold air (used for summer conditioning), $\eta_{\text {I summer }}$ is 0.68 . Therefore, the results show a 
co-generation second-principle yield lower than $\eta_{I}$ because of the difference between the thermal power to the condenser and the electrical power, but higher than $\eta_{I}$ in the case of electrical generation only. The major advantage associated with the co-generation respect to the power production must be compared to the higher costs of plant start-up and maintenance.

In the urban area of Potenza (the main town in Basilicata), the locations of the waste disposal, incineration and treatment plants aid the implementation of an interconnection system aimed at energy recovery. Thus, the best solution for the examined case is the integrated management of the energy sources, which entails (i) using the MSW combustible fraction; (ii) managing the landfill and (iii) stabilizing the wastewater treatment plant sludge. In fact, the thermal energy necessary for heating the anaerobic reactors as well as for evaporating percolates and digested sludge can be satisfied by cogeneration plant. Moreover, during summer, when cold is demanded for air-conditioning, it is possible to use an absorption refrigeration cycle, albeit such solution implies an increase in plant costs.

\section{Conclusions}

The rapid increase in volume and composition of MSW as a result of continuous economic growth, urbanization and industrialization is a problem for national and local governments, if they aim at ensuring an effective and sustainable management of waste. Solid waste incineration requires complex and sophisticated plants, whose running and installation costs are much higher than those of plants that work with traditional fuels. Moreover, energy recovery in fairly small-sized plants is affected by the high cost of the interventions.

The paper focuses on non-densely populated area where the production of urban waste is less than the urban ones. Considering the difficulties in waste collection due to geographic and demographic conditions, separated collection should be carried out only for complying with the regulations. The residual fraction should be sent to the incineration process for energy recovery, with positive environmental effects (in terms of GHGs emissions and landfill volumes) for the whole ISWM system.

Moreover, in low waste production area where the establishment of a unique MSW collection policy is difficult, the residual fraction quality is variable. Such issue can be solved with an appropriate pre-treatment process which improves the characteristics (e.g., heating value) of secondary fuel. The analysis of the obtained results in an Italian non-densely populated area demonstrates the potential of the co-generative incineration residual MSW for energy recovery after sieving, an effective and low cost pre-treatment process. Co-generative incineration is advantageous from an energetic point of view, especially considering the quality and the amount of the energy that can be obtained (power, heat and/or cold).

All these factors, including also the European regulations constraint and the low cost of secondary fuel which tends to increase its heating value, should be taken into account for a sustainable mid-term ISWM system planning in both developing and developed countries where the sustainable management of MSW cycle is penalized by the difficulties in source separated collection and the low flow of material recovery.

\section{Conflicts of Interest}

The authors declare no conflict of interest. 


\section{References}

1. United Nations-U.N. Environment Programme. Developing Integrated Solid Waste Management Plan; Training Manual; International Environmental Technology Centre: Osaka/Shiga, Japan, 2009; Volume 4.

2. Cossu, R.; Masi, S. Re-thinking incentives and penalties: Economic aspects of waste management in Italy. Waste Manag. 2013, 33, 2541-2547.

3. Callegari, A.; Torretta, V.; Capodaglio, A.G. Preliminary trial application of biological desulfonation in pig farms' anaerobic digesters. Environ. Eng. Manag. 2013, 12, 815-819.

4. Rada, E.C.; Ragazzi, M.; Torretta, V. Laboratory-scale anaerobic sequencing batch reactor for treatment of stillage from fruit distillation. Water Sci. Technol. 2013, 67, 1068-1074.

5. Martinez, S.L.; Torretta, V.; Minguela, J.V.; Siñeriz, F.; Raboni, M.; Copelli, S.; Rada, E.C.; Ragazzi, M. Treatment of slaughterhouse wastewaters using anaerobic filters. Environ. Technol. 2013, doi:10.1080/09593330.2013.827729.

6. Torretta, V.; Rada, E.C.; Istrate, I.A.; Ragazzi, M. Poultry manure gasification and its energy yield. UPB-Sci. Bull. Ser. D 2013, 75, 231-238.

7. Vaccari, M.; Torretta, V.; Collivignarelli, C. Effect of improving environmental sustainability in developing countries by upgrading solid waste management techniques: A case study. Sustainability 2012, 4, 2852-2861.

8. Hartmann, H.; Ahring, B.K. Anaerobic digestion of the organic fraction of municipal solid waste: Influence of co-digestion with manure. Water Res. 2005, 39, 1543-1552.

9. Chaerul, M.; Tnaka, M. A system dynamics approach for hospital waste management. Waste Manag. 2008, 28, 442-449.

10. Birpmar, M.E.; Bilgili, M.S.; Erdoğan, T. Medical waste management in Turkey: A case study of Istanbul. Waste Manag. 2009, 29, 445-448.

11. Abdulla, F.; Abu Qdais, H.; Rabi, A. Site investigation on medical waste management practices in northern Jordan. Waste Manag. 2008, 28, 450-458.

12. Mancini, G.; Tamma, R.; Viotti, P. Thermal process of fluff: Preliminary tests on a full-scale treatment plant. Waste Manag. 2010, 30, 1670-1682.

13. Torretta, V.; Istrate, I.; Rada, E.C.; Ragazzi, M. Management of waste electrical and electronic equipment in two EU countries: A comparison. Waste Manag. 2013, 33, 117-122.

14. Di Mauro, C.; Bouchon, S.; Torretta, V. Industrial risk in the Lombardy Region (Italy): What people perceive and what are the gaps to improve the risk communication and the partecipatory processes. Chem. Eng. Trans. 2012, 26, 297-302.

15. Morris, M.W.; Su, S.K. Social psychological obstacles in environmental conflict resolution. Am. Behav. Sci. 1999, 42, 1322-1349.

16. European Council. Directive 91/156/EEC Amending Directive 75/442/EEC on Waste; Official Journal L 078, 26/03/1991 P. 0032 - 0037; EEC: Brussels, Belgium, 1991.

17. European Council. Directive 91/689/EEC on Hazardous Waste; Official Journal L 377, 31/12/1991 P. 0020 - 0027; EEC: Brussels, Belgium, 1991.

18. European Parliament and Council. Directive 94/62/EC on Packaging and Packaging Waste; Official Journal L 365, 31/12/1994, P. 0010-0023; EC: Brussels, Belgium, 1994. 
19. European Parliament and Council. Directive 2000/76/EC on the Incineration of Waste; Official Journal L 332, 28/12/2000, P. 0091; EC: Brussels, Belgium, 2000.

20. Italian Parliament. Decreto Legislativo 5 febbraio 1997, n. 22 "Attuazione delle direttive 91/156/CEE sui rifiuti, 91/689/CEE sui rifiuti pericolosi e 94/62/CE sugli imballaggi e sui rifiuti di imballaggio". Available online: http:/www.parlamento.it/parlam/leggi/deleghe/97022dl.htm (accessed on 2 May 2013).

21. Italian Parliament. Decreto Legislativo 3 aprile 2006, n. 152 "Norme in materia ambientale". Available online: http://www.camera.it/parlam/leggi/deleghe/06152dl.htm (accessed on 2 May 2013).

22. Eriksson, O.; Carlsson, R.M.; Frostell, B.; Björklund, A.; Assefa, G.; Sundquist, J.-O.; Granath, J.; Baky, A.; Thyselius, L. Municipal solid waste management from a systems perspective. J. Clean. Prod. 2005, 13, 241-252.

23. Tascione, V.; Raggi, A. Identification and selection of alternative scenarios in LCA studies of integrated waste management systems: A review of main issues and perspectives. Sustainability 2012, 4, 2430-2442.

24. Bovea, M.D.; Ibáñez-Forés, V.; Gallardo, A.; Colomer-Mendoza, F.J. Environmental assessment of alternative municipal solid waste management strategies: A Spanish case study. Waste Manag. 2010, 30, 2383-2395.

25. De Feo, G.; Malvano, C. The use of LCA in selecting the best MSW management system. Waste Manag. 2009, 29, 1901-1915.

26. Iriarte, A.; Gabarrel, X.; Rieradevall, J. LCA of selective waste collection systems in dense urban areas. Waste Manag. 2009, 29, 903-914.

27. Emery, A.; Davies, A.; Griffiths, A.; Williams, K. Environmental and economic modelling: A case study of municipal solid waste management scenarios in Wales. Resour. Conserv. Recycl. 2007, 49, 244-263.

28. Chang, Y.H.; Chang, N.B. Compatibility analysis of material and energy recovery in a regional solid waste management system. J. Air Waste Manag. Assoc. 2003, 53, 32-40.

29. Di Maria, F.; Micale, C. Impact of source segregation intensity of solid waste on fuel consumption and collection costs. Waste Manag. 2013, 33, 2170-2176.

30. Nguyen, T.T.T.; Wilson, B.G. Fuel consumption estimation for kerbside municipal solid waste (MSW) collection activities. Waste Manag. Res. 2010, 28, 289-297.

31. European Commission. Eurostat Database. Available online: http://epp.eurostat.ec.europa.eu/ portal/page/portal/statistics/search_database (accessed on 1 December 2013).

32. Tchobanoglous, G.; Kreith, F. Handbook of Solid Waste Management; Mc-Graw-Hill: New York, NY, USA, 2002.

33. Murphy, J.D.; McKeogh, E. Technical, economic and environmental analysis of energy production from municipal solid waste. Renew. Energy 2004, 29, 1043-1057.

34. Rimaitytè, I.; Denafas, G.; Martuzevicius, D.; Kavaliauskas, A. Energy and environmental indicators of municipal solid waste incineration: Toward selection of an optimal waste management system. Pol. J. Environ. Stud. 2010, 19, 989-998.

35. Italian Institute of Statistics (ISTAT), Maps and Census Data (in Italian). Available online: http://www.istat.it/it/strumenti/cartografia (accessed on 23 April 2013). 
36. Institute for the Environmental Protection and Research-ISPRA. Rapporto rifiuti urbani (Municipal Waste Report); ISRRA: Rome, Italy, 2012.

37. Regione Basilicata. Piano regionale gestione rifiuti, Potenza, Italy. Available online: http://www.regione.basilicata.it/giunta/files/docs/DOCUMENT_FILE_242375.pdf (accessed on 20 April 2013).

38. Consonni, S.; Viganò, F. Material and energy recovery in integrated waste management systems: The potential for energy recovery. Waste Manag. 2011, 31, 2074-2084.

39. Valkenburg, C.; Gerber, M.A.; Walton, C.W.; Jones, S.B.; Thompson, B.L.; Stevens, D.J. Municipal Solid Waste (MSW) to Liquid Fuels Synthesis, Volume 1: Availability of Feedstock and Technology; U.S. Deptartment of Energy: Washington, DC, USA, 2008.

40. Cosmi, C.; Cuomo, V.; Macchiato, M.; Mangiamele, L.; Masi, S.; Salvia, M. Waste management modeling by MARKAL model: A case study for Basilicata Region. Environ. Model. Assess. 2000, 5, 19-27.

41. Cosmi, C.; Mancini, I.; Mangiamele, L.; Masi, S.; Salvia, M.; Macchiato, M. The management of urban waste at regional scale: The state of the art and its strategic evolution-Case study Basilicata Region (Southern Italy). Fresenius Environ. Bull. 2001, 10, 131-138.

42. Çengel, Y.A. Introduction to Thermodynamics and Heat Transfer; McGraw-Hill: New York, NY, USA, 2007.

43. Environmental Protection Agency_-Ireland. Municipal Solid Waste-Pre-treatment \& Residuals Management; IR-EPA: Wexford, Ireland, 2009.

44. Sue, D.C.; Chuang, C.C. Engineering design and energy analyses for combustion gas turbine based power generation system. Energy 2004, 29, 1183-1205.

45. Roher, A. Comparison of combined heat and power generation plants. ABB Review 1996, 3, $24-32$.

46. Lombardi, F.; Lategano, E.; Cordiner, S.; Torretta, V. Waste incineration in rotary kilns: A new simulation combustion's tool to support design and technical change. Waste Manag. Res. 2013, 31, 739-750.

(C) 2013 by the authors; licensee MDPI, Basel, Switzerland. This article is an open access article distributed under the terms and conditions of the Creative Commons Attribution license (http://creativecommons.org/licenses/by/3.0/). 